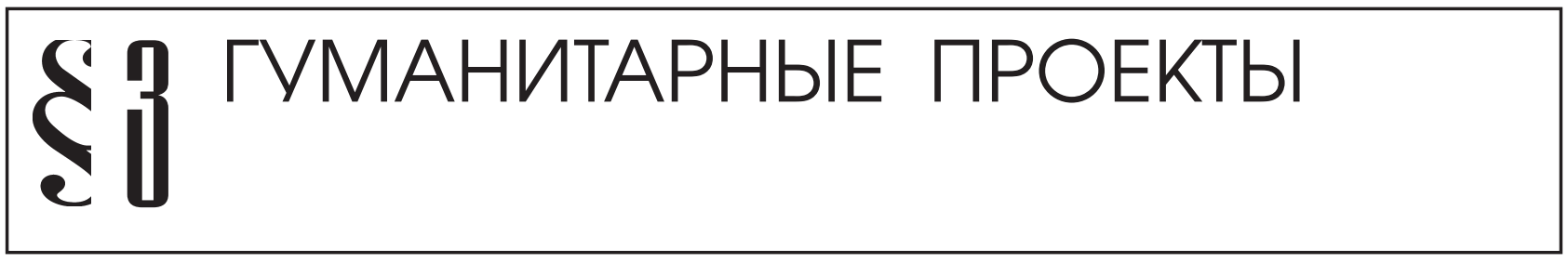

Петрова Л.Е.

\title{
ГУМАНИТАРНАЯ ЭКСПЕРТИЗА ПАЦИЕНТА: РЕАЛЬНОСТЬ ТЕОРЕТИЧЕСКОГО КОНСТРУКТА
}

\begin{abstract}
Аннотация: Гуманитарная экспертиза паџиента рассматривается с точки зрения эффективности взаимодействия в процессе оказания медичинской помощи. Разведывательное сочиологическое исследование среди экспертов (очное и онлайн анкетирование, вторичный анализ данных) показало, что медики считают гуманитарную экспертизу пациента востребованной, но не обеспеченной технологически. Содержание гуманитарной экспертизы пациента близко к определению репертуара сочиальной роли пачиента: это оценка иенностей, ресурсов, потенциала сотрудничества между врачом и пациентом. Обосновано доминирование соииальных характеристик пациента в производстве гуманитарной экспертизы над психологическим портретированием. Полученные выводы могут использоваться в первую очередь для планирования содержания образовательных программ в профессиональной медицинской школе.

Review: Humanitarian expertise of a patient is viewed from the point of view of effective interaction in the process of medical aid. Opinion survey of experts (face-to-face and online questionnaire and the secondary analysis of data) showed that medical workers believe humanitarian expertise of patients to be quite important but not always technologically possible. Humanitarian expertise of a patient is close to defining the scope of his social roles and includes evaluation of values, resources and potentials of cooperation between a doctor and a patient. The author of the article proves the dominating role of the patient's social dimensions in humanitarian expertise compared to creation of a psychological portrait, for instance. The results of research can be used for planning contents of the educational curriculum at professional medical schools.
\end{abstract}

Ключевые слова: Социология, пациент, врач, гуманитарная, экспертиза, компетентность, профессионализм, анкетирование, гуманизаиия, образование

Keywords: social studies, patient, doctor, humanitarian, expertise, competence, professionalism, questionnaire survey, humanization, education.

$\Pi$ онятие «гуманитарная экспертиза» активно разрабатывается отечественными исследователями, в основном в дисциплинарном поле философии. Благодаря публикациям Б.Г. Юдина, В.А. Лукова, П.Д. Тищенко, Г.Л. Тульчинского и др. тематика производства гуманитарной экспертизы, необходимость, возможности и ограничения такой технологии описаны хорошо. К сожалению, имеется мало примеров реализации таких проектов: к таким редким исключениям относится, например, проект гуманитарной экспертизы социологического исследования поведения подростков, описанный Г.Б. Степановой [13]. В то же время хотя в социологическом категориальном аппарате термин «гуманитарная экспертиза» отсутствует, он весьма комплементарен таким широко используемым понятиям, как социокультурный анализ, клинический подход в исследованиях и др.

Большое инструментальное значение термин «гуманитарная экспертиза пациента» (здесь и далее будем использовать аббревиатуру: ГЭП) имеет в исследованиях профессионализма врачей. Последние включают в себя и этапы профессиональной социализации (в том числе в образовании), и трансформацию профессионализма в повседневных практиках (из идеала - в реальность), и редукцию институциональных изменений. При использовании конструкта ГЭП появляется возможность описать технологически эффекты взаимодействия на приеме, консультации, так как именно клиническое интервью, про- 
водимое врачом общемедицинской практики, до сих пор является самой распространенной ситуацией «медицинского нарратива». Именно дефицит «гуманитарности» признается проблемой, источником неудовлетворенности качеством российской медицины, поскольку пациентам кажется, что их на приеме врачи не хотят «ни видеть, ни слышать».

Обсуждение гуманитарной экспертизы в контексте биоэтики и этики проводилось на протяжении нескольких лет сотрудниками ИФ РАН и представлено в виде многочисленных публикаций, в частности, 5-и вышедших сборниках [16], а итоги этой работы представлены в обзорной статье А.А. Воронина [7]. Действительно, границы этики и гуманитарной экспертизы крайне тонки. Однако это так в случае макро-и мезоуровня экспертной оценки: проекты, реформы, законы и пр., а ГЭП как технология осуществляется на микроуровне - на уровне взаимодействия между врачом и пациентом во время клинического интервью, в момент оказания медицинской помощи, являясь частью последней, призванной эту помощь сделать более эффективной, а взаимодействие между врачом и пациентом - более приемлемым для обеих сторон с точки зрения эмоциональных затрат и результатов.

ГЭП близка содержательно, но далека институционально от медико-социальной экспертизы - «определения в установленном порядке потребностей освидетельствуемого лица в мерах социальной защиты, включая реабилитацию, на основе оценки ограничений жизнедеятельности, вызванных стойким расстройством функций организма» [15].

Негативные последствия отсутствия ГЭП можно обнаружить в многочисленных исследованиях, характеризующих взаимодействие между врачом и пациентом. Вообще, проблематика коммуникативной культуры врача достаточно хорошо разработана. Но, видимо, «воз и ныне там»: именно неэффективная коммуникация зачастую оказывается источником неудовлетворенности пациентов оказанной медицинской помощью. Возможно, дело здесь в отсутствии ГЭП? Вот кейс из недавнего исследования, проведенного в Омске, где методом анкетирования были опрошены врачи по довольно большой по объему выборке. Предмет исследования - трудности работы с пожилыми пациентами. Не стоит много говорить о том, насколько актуальна рефлексия по поводу медицинской помощи пожилым людям: эта социальная группа увеличивается, объем гуманитарных проблем у них не меньше, чем биологических, и именно пожилые составляют значительную долю контингента в ЛПУ, особенно - в государственной медицине. «Большинство опрошенных врачей отметили, что пожилые пациенты обращаются за медпомощью значительно чаще, чем граждане трудоспособного возраста, но только 58,3\% [опрошенных] считают обращения обоснованными, а 22,9\% фиксируют, что иногда отсутствует повод для обращения. Среди последних значительная часть участковых врачей $(30,4 \%) »[11$, с. 14$]$.

Пожилой пациент (при всей своей уязвимости) обладает еще меньшим объемом власти во взаимодействии с врачом по сравнению с другими группами: по результатам опроса выявлено, что 5,3\% врачей не согласовывают тактику лечения с пожилым пациентом вообще, иногда $-26,4 \%$. Лишь половина врачей $(45,7 \%)$ всегда согласовывают стоимость лечения, а 34,2\% - только при назначении дорогостоящих препаратов.

Показательно, что профессионалы реалистично оценивают негативные последствия от общения со столь специфическим (но - мы помним - распространенным) контингентом: «Характерологические особенности пожилых пациентов признают раздражающим фактором для себя $56,3 \%$ опрошенных врачей».

Врачи не могут не знать особенности пожилых, не могут не фиксировать (на уровне визуального осмотра, беседы на приеме, сколь бы короткой она не была) уровень депривации (социальной, культурной, коммуникативной), мотивационный профиль пациента. Это и есть элементы ГЭП, которая производится в данном случае на приеме и может позитивно повлиять и на качество оказанной медицинской помощи, и на удовлетворенность работой врачей. Гуманитарная экспертиза пациента - это не самостоятельно, специально организованная деятельность, а часть профессиональной активности врача в его общении с человеком, обратившимся за медицинской помощью. Целью ГЭП является описание рисков при следовании или неследовании пациентом рекомендациям врача, что в конечном 


\section{Политика и общество 10 (106) • 2013}

итоге должно определяться оценкой перспектив благополучия человека как личности.

Впервые термин ГЭП мы привели в публикации [12], посвященной опыту использования интерактивных технологий в преподавании вузовской дисциплины «Социология медицины». Луков Вал.А. отмечал, что в настоящее время «стихийно гуманитарная экспертиза уже существует, хотя ее институционализация находится в начальной стадии» [10, с. 63]. Думается, мы именно «стихийно» стали использовали это словосочетание, а оформление подхода состоялось позднее.

В частности, в октябре 2012 года в Уральской государственной медицинской академии (УГМА) было проведено анкетирование студентов 1, 3 и 5 курсов двух факультетов - педиатрического и лечебно-профилактического $(\mathrm{n}=625)$. Исследование было посвящено установкам студентов-медиков на общекультурные компетенции. Респондентам был задавался вопрос «Что для вас как для будущего врача и человека (личности) важно, а что - менее важно в получаемом в медвузе образовании?» с тремя вариантами ответа: «важно», «неважно», «затрудняюсь ответить». Всего было предложено 16 позиций для оценивания, в том числе - «умение проводить ГЭП».

Подавляющее большинство будущих врачей высоко оценили умение проводить ГЭП: 85\% считают это важным в профессии, 53\% опрошенных указали, что это важно и в жизни.

Высокие оценки указанной компетенции можно считать маркером выраженных установок студентов-медиков на рассматриваемый феномен. Однако, интерпретируя эти данные, следует учесть, что студенты вообще продемонстрировали высокий уровень установок на социально-гуманитарные компетенции, предложенные в анкете (оценки «важно» варьируются от 98\% до 41\%). То есть установки студентов-медиков крайне позитивны - почти все общекультурные (они же социально-гуманитарные) компетенции оцениваются высоко.

В январе 2013 года методом онлайн анкетирования был проведен опрос экспертов - практикующих врачей и преподавателей медвуза, ведущих научную работу. Всего опрошен 21 чел., в том числе 13 женщин и 8 мужчин, половина опрошенных имеет стаж работы в медицине до 10 лет, треть - 11-20 лет. Такие особенности экс- пертной группы, как высокая мотивация в профессии и наличие рефлексии над проблемами современного российского здравоохранения, позволяет считать полученные данные валидными на уровне разведывательного исследования.

На вопрос «Вам известно понятие «ГЭП»?» двое из экспертов ответили «да» $\left(10 \%{ }^{1}\right)$. Большинство же дали отрицательный ответ (19 чел. =90\%).

Следующий вопрос был открытым и формулировался так: «Термин «ГЭП» входит в научный оборот. Пожалуйста, напишите, как Вы лично понимаете, что это такое?». Трое экспертов (14\%) написали «не знаю, непонятно». Один ответ «наверное, это составляющая от базовых слов». Еще один эксперт весьма критично оценил наши усилия, написав, что ГЭП - это «ненужный термин, придуманный социологами». Таким образом, в нашем распоряжении оказалось 14 содержательных ответов в среднем по 9 слов в высказывании. Методом открытого кодирования мы произвели анализ представленных экспертами определений и сгруппировали их. В табл. 1 представлен первичный материал и результаты интерпретации.

Первая группа определений описывает стиль - ответ на вопрос «КАК»: «человеческий» подход к пациенту, «осмотр пациента по-доброму, вежливо».

Вторая группа определений указывает на технологию портретирования и отвечает на вопрос «КТО»: оценка социальной активности, образования, культуры, характера, психологического типа пациента.

Третья группа описывает взаимодействие, определения здесь инструментальны, технологичны и отвечают на вопрос «ЗА СЧЕТ ЧЕГО»: учет отношения к врачу, интересов, ресурсов пациента, значения болезни для него, способности понять информацию от врача.

Последняя группа экспертных определений это классическое (по Т.Парсонсу) описание социальной роли больного, который должен быть освобожден от нормальных социальных обязан-

\footnotetext{
1 Здесь и далее мы будем приводить в том числе относительные числа - проценты - для простоты восприятия информации. Естественно, что объем выборки - 21 чел. - не позволяет говорить о значимости статистических распределений.
} 
ностей (ролей); не в состоянии о себе заботиться; как правило, желает возвратиться к нормальной жизни (то есть принимает роль больного как временную); обращается за компетентной профессиональной помощью. Именно проведя ГЭП, можно судить о том, как эта роль выполняется, реализуется, не становится ли доминирующей идентичностью вместо временного статуса. Т.Парсонса неоднократно критиковали за идеа- лизированное, упрощенное представление о поведении человека в ситуации нарушения здоровья, однако никто не поспорит с актуальностью рассматриваемой проблематики. Правда, в современных исследованиях социальная роль больного (пациента) представлена дифференцированно: так, нельзя сравнивать «роль острого больного», «роль хронического больного», «роль безнадежно больного».

Таблицьа 1

Содержание понятия "гуманитарная экспертиза пацчиента» в оценках экспертов

\begin{tabular}{|c|c|c|}
\hline $\begin{array}{c}\text { Решаемая в ГЭП } \\
\text { задача }\end{array}$ & $\begin{array}{c}\text { Кол-во } \\
\text { высказываний }\end{array}$ & $\begin{array}{c}\text { Цитаты из ответов экспертов на открытый вопрос } \\
\text { (даны в лексике экспертов) }\end{array}$ \\
\hline $\begin{array}{l}\text { Психологическое } \\
\text { портретирование. } \\
\text { Учет личностных } \\
\text { особенностей, } \\
\text { психологическая } \\
\text { типизация } \\
\text { пациента. }\end{array}$ & 7 & $\begin{array}{l}\text { - оценка пациента как личности, его культурологические } \\
\text { особенности и социальные даннье, может быть-уровень } \\
\text { образования; } \\
\text { - оценка совокупности иченностного подхода к личности } \\
\text { пациента; } \\
\text { - составление психологического типа пациента; } \\
\text { - оценка пациента в комплексе какличность; } \\
\text { - это моя оценка характерологических особенностей } \\
\text { пациента, его личностных качеств; } \\
\text { - оценка общееобразовательного и культурного уровня } \\
\text { пациента. }\end{array}$ \\
\hline $\begin{array}{l}\text { Эффективное } \\
\text { взаимодействие на } \\
\text { основе социального } \\
\text { портретирования - } \\
\text { описания ресурсов, } \\
\text { социальной } \\
\text { роли и стиля } \\
\text { ее реализации. } \\
\text { Аудит потенциала } \\
\text { партнерства врача и } \\
\text { пациента. }\end{array}$ & 5 & $\begin{array}{l}\text { - выяснение отношения пациента к деятельности врача; } \\
\text { - этическая и моральная оценка состояния пациента с } \\
\text { учетом значения для него болезни; } \\
\text { - насколько пациент нуждается в помощуи, на какие } \\
\text { препарать он может рассчитывать; } \\
\text { - экспертиза пациента с точки зрения учета интереса } \\
\text { пациентов; } \\
\text { - оценка способностей пациентов понимать сообщаемую } \\
\text { ему информацию. }\end{array}$ \\
\hline $\begin{array}{l}\text { Эффективность } \\
\text { медицинской } \\
\text { помощи основана } \\
\text { на «дружественной } \\
\text { ориентации». }\end{array}$ & 2 & $\begin{array}{l}\text { - «человеческий» подход к пацчиенту; } \\
\text { - осмотр пациента по-доброму, вежливо. }\end{array}$ \\
\hline
\end{tabular}




\section{Политика и общество 10 (106) 2013}

Надо признать, что ни одна из трех указанных процедур не имеет технологически описанной методики. Как показал наш опыт обсуждения с профессионалами-медиками типов пациентов [13], врачам психологические характеристики гораздо важнее социальных. С другой стороны, позиция о ГЭП как технологии эффективного взаимодействия - более инструментальна, «вписывается» в рабочую повседневность врача.

Процессы медикализации привели к тому, что современный человек живет в обществе ремиссии, в разной степени хронизирован в отношении здоровья. И причины медицинской объективации - не психологические, а социальные - институциональное и социетальное давление, помноженное на объем социального капитала.

Реальность изучаемого феномена мы измеряли с помощью закрытого вопроса «По вашему личному и профессиональному опыту, производят ли врачи ГЭП?». Двое опрошенных экспертов (десятая часть) ответили «да, всегда», третья часть (33\%) - «да, редко», еще двое (10\%) «никогда не производят. Половина опрошенных (48\%) затруднились с ответом.

Далее мы попросили экспертов оценить по 10-балльной шкале, должна ли ГЭП стать обязательной. Низкие баллы оценки обязательности ГЭП дал каждый четвертый эксперт, средние баллы - 6 экспертов (29\%), высокие - 10 экспертов, т.е. почти половина опрошенных. В среднем, оценки сосредоточены в середине шкалы, что можно интерпретировать как осторожную позицию участников опроса.

С помощью закрытого вопроса мы предложили экспертам предположить, что может стать препятствием для обеспечения ГЭП в работе современного врача. На первом месте - дефицит времени на приеме - такой ответ дали подавляющее большинство опрошенных экспертов 17 (81\%). С большим отрывом вариант ответа «непрофессионализм врача» - так считают 8 экспертов (38\%). Еще 7 экспертов (33\%) считают барьером для обеспечения ГЭП отсутствие медицинских стандартов по этому поводу.

По 2 эксперта выбрали следующие варианты ответа: «нет необходимости в такой работе», «пациентам не нужна гуманитарная экспертиза», «гуманитарная экспертиза нужна, но делать ее должны другие специиалисты». Это указывает на в целом позитивную реакцию на перспективы ГЭП - лишь четверо (пятая часть) из опрошенных экспертов резко отрицают саму возможность такой работы.

Таким образом, разведывательное исследование показало, что врачи осознают необходимость ГЭП, считают ее востребованной процедурой в отечественной практике взаимодействия между врачом и пациентом. Однако барьеры ее осуществления велики: ресурсный дефицит, технократизация процесса оказания медицинской помощи, жесткое следование нормативным процедурам и др.

Полученные данные в совокупности с методологическим базисом описания проблемы являются платформой для подготовки технологии ГЭП.

Как отмечают Киященко Л.П. и Тищенко П.Д. [8], гуманитарная экспертиза касается оценки гуманитарных последствий принимаемых решений. По отношению к пациенту это также справедливо. Комплементарность гуманитарной экспертизы и гуманизма указывает и на то, что задача ГЭП состоит в оценке перспектив благополучия последнего, что во многом определяет рекомендации врача. Ни у кого не вызывает недоумения термин «гуманитарная катастрофа», а русскоязычный философствующий читатель уже не удивляется термину «гуманитарная экспертиза». У нас нет особых надежд на тотальное введение в отечественную медицинскую практику гуманитарной экспертизы пациента как технологии российским врачам не до того. Думается, именно за счет гуманитаризации медицинского профессионального образования (как додипломного, так и последипломного) можно и нужно популяризировать ГЭП.

Высокая степень социальной дифференциации в российском обществе указывает на важность для врача аудита именно социальных ресурсов объема депривации, установок на самосохранительное поведение, стилевых предпочтений в методах лечения и профилактики и пр.

В условиях постоянного реформирования образования и практики в отечественном здравоохранении надежды на институциализацию ГЭП невелики, но технологическая основа такой профессиональной компетенции может закладываться в циклах гуманитарных и социально-экономических дисциплин в вузах. Также 
формирование представлений о технологиях ГЭП и ее производство - безусловно, дело честолюбивого профессионала-медика, который стремится к конкуренции за «удобного» пациента - мотивированного, адекватно воспринимающего информацию, обладающего хотя бы минимальным набором материальных ресурсов для лечения.

Наверное, любой исследователь, оказавшись пациентом (про себя могу сказать определенно), будет мечтать о нарративной медицине и захочет представить свою историю боли, болезни, дисфункциональности. Примером тому могут служить статьи Лехциера В.Л., как реферирующие дебаты об этом феномене, так и представляющие самостоятельный взгляд автора на «раненого рассказчика» [9]. В таком варианте общения между врачом и пациентом фабулизация как основа для дифференциального диагноза и будет предполагать гуманитарную экспертизу пациента. Нарратив же шире гуманитарной экспертизы пациента, но является ее атрибутом.

\section{Библиография:}

1. Биоэтика и гуманитарная экспертиза. Вып. 6 / Рос. акад. наук, Ин-т философии ; Отв. ред. Ф.Г. Майленова. М.: ИФРАН, 2012.

2. Биоэтика и гуманитарная экспертиза. Вып. 5 / Рос. акад. наук, Ин-т философии ; Отв. ред. Ф.Г. Майленова. М.: ИФРАН, 2011.

3. Биоэтика и гуманитарная экспертиза. Вып. 4 / Рос. акад. наук, Ин-т философии ; Отв. ред. Ф.Г. Майленова. М.: ИФРАН, 2010.

4. Биоэтика и гуманитарная экспертиза: комплексное изучение человека и виртуалистика. Вып. 3 / Рос. акад. наук, Ин-т философии ; Отв. ред. Ф.Г. Майленова. М.: ИФРАН, 2009.

5. Биоэтика и гуманитарная экспертиза: Пробл. геномики, психологии и виртуалистики. Вып. 2 / Рос. акад. наук, Ин-т философии ; Отв. ред. Ф.Г.Майленова. - М.: ИФ РАН, 2008.

6. Биоэтика и гуманитарная экспертиза: Пробл. геномики, психологии и виртуалистики / РАН. Ин-т философии; Отв. ред. Ф.Г. Майленова. М.: ИФ РАН, 2007.
7. Воронин А.А. Гуманитарная экспертиза (обзор) // Философия и культура. 2012. № 5 (53).

8. Киященко Л.П., Тищенко П.Д. Матрица субъект-предметного различения (вариации на тему гуманитарной компетентности) // Знание. Понимание. Умение. 2011. № 4.

9. Лехциер В.Л. Раненый рассказчик: на пути к нарративной медицине // Вестник СамГУ. 2010. № 5 (79).

10. Луков Вал.А. Гуманитарная экспертиза: от теории - к практике // Наукові і освітянські методології та практики: іноваційний проект. http://cgo.irbis-nbuv.gov.ua

11. Мальцев С.Н. О негативных особенностях лечения пожилых пациентов // Клиническая геронтология. 2012. № 7-8.

12. Петрова Л.Е. Мировой и отечественный опыт использования интерактивных технологий в преподавании вузовской дисциплины «Социология медицины» // Инновационные образовательные технологии: Материалы Международного интерактивного форума, 2-5 мая 2012 г. Екатеринбург, 2012.

13. Петрова Л.Е. Типологизация пациентов в российских и зарубежных социологических исследованиях: сравнительный анализ // Бюллетень патологии и физиологии дыхания. 2011. Вып. 39, март.

14. Степанова Г.Б. Опыт гуманитарной экспертизы социологического исследования поведения подростков (материалы Круглого стола) // Биоэтика и гуманитарная экспертиза. Вып. 2 /Рос. акад. наук, Ин-т философии; Отв. ред. Ф.Г. Майленова. М.: ИФРАН, 2008. С. 129-159.

15. Федеральный закон «О социальной защите инвалидов в Российской Федерации» № 181 Ф3 от 24.11.1995, ст. 7.

\section{References (transliteration):}

1. Bioetika i gumanitarnaya ekspertiza. Vyp. 6 / Ros. akad. nauk, In-t filosofii ; Otv. red. F.G. Mailenova. M.: IFRAN, 2012.

2. Bioetika i gumanitarnaya ekspertiza. Vyp. 5 / Ros. akad. nauk, In-t filosofii ; Otv. red. F.G. Mailenova. M.: IFRAN, 2011. 


\section{Политика и общество 10 (106) • 2013}

3. Bioetika i gumanitarnaya ekspertiza. Vyp. 4 / Ros. akad. nauk, In-t filosofii ; Otv. red. F.G. Mailenova. M.: IFRAN, 2010.

4. Bioetika i gumanitarnaya ekspertiza: kompleksnoe izuchenie cheloveka i virtualistika. Vyp. 3 / Ros. akad. nauk, In-t filosofii ; Otv. red. F.G. Mailenova. M.: IFRAN, 2009.

5. Bioetika i gumanitarnaya ekspertiza: Probl. genomiki, psikhologii i virtualistiki. Vyp. 2 / Ros. akad. nauk, In-t filosofii ; Otv. red. F.G.Mailenova. - M.: IF RAN, 2008.

6. Bioetika i gumanitarnaya ekspertiza: Probl. genomiki, psikhologii i virtualistiki / RAN. In-t filosofii; Otv. red. F.G. Mailenova. M.: IF RAN, 2007.

7. Voronin A.A. Gumanitarnaya ekspertiza (obzor) // Filosofiya i kul’tura. 2012. № 5 (53).

8. Kiyashchenko L.P., Tishchenko P.D. Matritsa sub' 'ekt-predmetnogo razlicheniya (variatsii na temu gumanitarnoi kompetentnosti) // Znanie. Ponimanie. Umenie. 2011. № 4.

9. Lekhtsier V.L. Ranenyi rasskazchik: na puti k narrativnoi meditsine // Vestnik SamGU. 2010. № 5 (79).
10. Lukov Val.A. Gumanitarnaya ekspertiza: ot teorii - k praktike // Naukovi i osvityans'ki metodologii ta praktiki: inovatsiinii proekt. http://cgo.irbis-nbuv.gov.ua

11. Mal'tsev S.N. O negativnykh osobennostyakh lecheniya pozhilykh patsientov // Klinicheskaya gerontologiya. 2012. № 7-8.

12. Petrova L.E. Mirovoi i otechestvennyi opyt ispol'zovaniya interaktivnykh tekhnologii v prepodavanii vuzovskoi distsipliny «Sotsiologiya meditsiny» // Innovatsionnye obrazovatel'nye tekhnologii: Materialy Mezhdunarodnogo interaktivnogo foruma, 2-5 maya 2012 g. Ekaterinburg, 2012.

13. Petrova L.E. Tipologizatsiya patsientov v rossiiskikh i zarubezhnykh sotsiologicheskikh issledovaniyakh: sravnitel'nyi analiz // Byulleten' patologii i fiziologii dykhaniya. 2011. Vyp. 39, mart.

14. Stepanova G.B. Opyt gumanitarnoi ekspertizy sotsiologicheskogo issledovaniya povedeniya podrostkov (materialy Kruglogo stola) // Bioetika i gumanitarnaya ekspertiza. Vyp. 2 /Ros. akad. nauk, In-t filosofii; Otv. red. F.G. Mailenova. M.: IFRAN, 2008. S. 129-159. 